\title{
FENO AND ATOPY IN PEDIATRIC ASTHMA
}

\author{
Cristiana Stanciulescu ${ }^{1}$, Mirela Chiru ${ }^{1,2}$, Alina Oprea ${ }^{1}$, Daniela Pacurar ${ }^{1,2}$, \\ Carmen Zapucioiu ${ }^{1,2}$, Elena Petrisor ${ }^{1}$, Dumitru Oraseanu ${ }^{1,2}$ \\ 1 "Grigore Alexandrescu”" Emergency Clinical Hospital for Children, Bucharest \\ 2 "Carol Davila" University of Medicine and Pharmacy, Bucharest
}

\begin{abstract}
Objectives. The aim of this study was to determine the manner in which the level of exhaled nitric oxide (FENO) influences the atopic status in children with asthma.

Methods. The study included 92 asthmatic children (aged 5-18 years) admitted on the Pediatric Clinic of "Grigore Alexandrescu" Emergency Clinical Hospital for Children. The atopic status was evaluated through anamnesis, clinical examination and laboratory determination of serum eosinophils and total Ig $\mathrm{E}$. All children underwent measurement of FENO.

Results. Children with atopic asthma had higher levels of FENO than children with nonatopic asthma. The FENO values correlate with eosinophilia and high values of immunoglobulin E.

Conclusion. FENO is a useful marker for the evaluation of airway inflammation in children with atopic asthma.
\end{abstract}

Keywords: FENO, eosinophilia, IgE, asthma, atopy

\section{INTRODUCTION}

Asthma is a chronic, heterogeneous disease with an incomplete known pathogeny which incriminates especially the persistent airway inflammation. Nitric oxide is a marker that evaluates this particular inflammation and has been more and more used as a biomarker for the various phenotypes of asthma (1). FENO correlates with the atopic status and quantifies the severity of airway inflammation. High levels of nitric oxide are pathognomonic for eosinophilic inflammation (2). Studies have shown that patients with atopic asthma have higher levels of FENO (3).

\section{PURPOSES AND OBJECTIVES}

The increase in nitric oxide values correlates with the increase of serum inflammatory cytokines. (4). The aim of the study performed in our clinic was to establish a correlation between the level of FENO and the anamnestic, clinical, laboratory data relevant for atopic status. We also wanted to outline the contribution of FENO to the definition of the allergic phenotype of asthma in children.

\section{MATERIALS AND METHODS}

Our study included a group of 92 children previously diagnosed with asthma (code ICD 10 from 2014-J 45) with ages between 5 and 18. The study was performed in the Pediatric Clinic of "Grigore Alexandrescu" Emergency Clinical Hospital for Children from January 2013 to January 2014 with the approval of the Medical Ethical Commission of the hospital. The exclusion criteria were: (i) poor compliance and incorrect technique during measurement of FENO; (ii) acute upper respiratory infection at the time of examination. The patients were divided into two subgroups according to their age: 5-12 and 13-18. Both subgroups were analyzed depending on the history for atopy, serum eosinophiles, total immunoglobulin $\mathrm{E}$ and FENO.

Corresponding author:

Cristiana Stanciulescu, "Grigore Alexandrescu” Emergency Clinical Hospital for Children, 30-32 lancu de Hunedoara Boulevard, Bucharest

E-mail: cristianastanciulescu@yahoo.com 
Clinical examination also included a complete ENT examination in order to identify allergic ailments such as allergic rhinitis.

\section{STATISTICAL ANALYSIS}

Statistical analysis was performed using the statistical software SPSS for Windows 21.0 (IBM SPSS, IBM Ireland, Dublin, Ireland). The normal distributed quantitative variables were expressed as means \pm standard error of mean (SEM) and analyzed by using Student T-test or Oneway Anova analysis with LSD Post-hoc test. Crosstabs distribution with chi-squared $\left(\chi^{2}\right)$ analysis was performed to evaluate the differences between logistic data. Parametric bivariate correlation analysis of FENO with eosinophils and IgE was performed using the Pearson's function. Multiple linear regression models of the FENO levels (as dependent variable) with serum IgE and blood eosinophils (as independent variables) were estimated and the significant adjusted R-squared estimates were used as prediction score for the FENO variance (with checking for the model correction by using F-function score and Durbin-Watson analysis). Binary logistic regression (LR) analysis with the enter iteration method for the discrimination between $\mathrm{AB}$ groups was done using non-allergic $\mathrm{AB}$ group considered as reference category and allergic $\mathrm{AB}$ group as risk category, while FENO (ppb), eosinophils (\% num), $\mathrm{IgE}(\mathrm{IU} / \mathrm{ml})$, age group, gender, atopy, rhynitis, familial atopy history were introduced in the LR model as covariates. The threshold for statistical significance was set to $5 \%(\mathrm{p}<0.05)$.

\section{RESULTS}

The distribution of allergic asthma on the two subgroups did not identify statistical differences according to age group, to the presence of atopy, rhinitis or family history positive for atopy $(\mathrm{p}>0.05$, Table no 1). However, the diagnosis of rhinitis has a significant contribution (OR 3.261), 28.1\% being diagnosed with allergic asthma, while only $10.7 \%$ had non-allergic asthma. On the other hand, this distribution is not statistically significant, perhaps as a result of the number of cases. The mean values of the measured parameters FENO, eosinophils and Ig $\mathrm{E}$ differ according to the diagnosis of allergic asthma, being statistically significant higher in this subgroup than in the subgroup with non-allergic asthma $(\mathrm{p}<0.05$, Table 1$)$.
TABLE 1. Mean values of the parameters measured for the subgroups of studied patients

\begin{tabular}{|c|c|c|c|}
\hline Parameter & Subgroup & Mean \pm SEM & p-value \\
\hline FENO (ppb) & $\begin{array}{l}\text { Asthma } \\
\text { Non-allergic } \\
\text { Allergic } \\
\text { Age } \\
5-12 \mathrm{yr} \\
13-18 \mathrm{yr} \\
\text { Atopy } \\
\text { No } \\
\text { Yes } \\
\text { Rhinitis } \\
\text { No } \\
\text { Yes } \\
\text { Total ( } \mathrm{n}=92)\end{array}$ & $\begin{array}{c}11.67 \pm 2.47 \\
26.26 \pm 4.76 \\
18.62 \pm 3.02 \\
35.12 \pm 11.59 \\
19.39 \pm 2.96 \\
29.24 \pm 10.48 \\
22.81 \pm 4.12 \\
17.52 \pm 3.64 \\
21.54 \pm 3.25\end{array}$ & $\begin{array}{c}0.212 \\
0.340 \\
-\end{array}$ \\
\hline $\begin{array}{l}\text { Eosinophils } \\
\text { (\% num) }\end{array}$ & $\begin{array}{l}\text { Asthma } \\
\text { Non-allergic } \\
\text { Allergic } \\
\text { Age } \\
5-12 \mathrm{yr} \\
13-18 \mathrm{yr} \\
\text { Atopy } \\
\text { No } \\
\text { Yes } \\
\text { Rhinitis } \\
\text { No } \\
\text { Yes } \\
\\
\text { Total }(n=92) \\
\end{array}$ & $\begin{array}{l}0.0423 \pm 0.00711 \\
0.0640 \pm 0.00689 \\
0.0551 \pm 0.00585 \\
0.0625 \pm 0.01247 \\
0.0539 \pm 0.00608 \\
0.0641 \pm 0.01066 \\
0.0586 \pm 0.00637 \\
0.0500 \pm 0.00918 \\
0.0564 \pm 0.00527\end{array}$ & $\begin{array}{r}0.032^{*} \\
0.591 \\
0.411 \\
0.443 \\
- \\
\end{array}$ \\
\hline IgE (IU/ml) & $\begin{array}{l}\text { Asthma } \\
\text { Non-allergic } \\
\text { Allergic } \\
\text { Age } \\
5-12 \mathrm{yr} \\
13-18 \mathrm{yr} \\
\text { Atopy } \\
\text { No } \\
\text { Yes } \\
\text { Rhinitis } \\
\text { No } \\
\text { Yes } \\
\\
\text { Total }(n=92)\end{array}$ & $\begin{array}{c}74.31 \pm 13.32 \\
490.45 \pm 60.23 \\
354.43 \pm 54.71 \\
496.40 \pm 95.20 \\
398.08 \pm 61.23 \\
322.81 \pm 57.75 \\
430.47 \pm 62.61 \\
242.03 \pm 48.40 \\
379.49 \pm 48.23\end{array}$ & $\begin{array}{l}0.374 \\
0.020 *\end{array}$ \\
\hline
\end{tabular}

Mean values and mean standard deviation error (SEM) of analysed parameters, with evaluation of statistic difference with T-test Student (threshold $\mathrm{p}<0.05$ ), after the analysis of the equality of variations (Levene test) $* p<0.05, * * p<0.01, * * * p<0.001$.

The values of FENO statistically correlate with the blood levels of eosinophils and $\operatorname{Ig} E(p<0.05$, Table 2). The correlation analysis of the subgroups reveals that FENO correlates statistically significant with eosinophils but not with $\operatorname{IgE}$ for patients with allergic asthma. In addition, FENO correlates with eosinophils and Ig E for the 13-18 years age subgroup.

The use as an independent biomarker of FENO for allergic asthma can be estimated on the basis of the variation of other associated parameters used for diagnosis. Multiple linear regression analysis 
TABLE 2. Statistical correlations between FENO (ppb) and the parameters measured in the subgroups of studied patients

\begin{tabular}{|l|l|c|c|}
\hline Parameter & Subgroup & \multicolumn{1}{|c|}{$\mathbf{R}$} & p-value \\
\hline $\begin{array}{l}\text { Eosinophils } \\
\text { (\% num) }\end{array}$ & Asthma & & \\
& Non-allergic & 0.211 & 0.359 \\
& Allergic & 0.263 & $0.043^{*}$ \\
& Age & & \\
& $5-12 \mathrm{yr}$ & 0.221 & 0.074 \\
& $13-18 \mathrm{yr}$ & 0.514 & $0.050^{*}$ \\
& Atopy & & \\
& No & 0.404 & $0.001^{* *}$ \\
& Yes & 0.097 & 0.685 \\
& Total (n =92) & $\mathbf{0 . 2 8 7}$ & $\mathbf{0 . 0 1 0 ^ { * * }}$ \\
\hline IgE (IU/ml) & Asthma & & \\
& Non-allergic & 0.446 & 0.056 \\
& Allergic & 0.181 & 0.167 \\
& Age & & \\
& 5-12 yr & 0.073 & 0.564 \\
& 13-18 yr & 0.673 & $0.006^{* *}$ \\
& Atopy & & \\
& No & 0.238 & 0.060 \\
& Yes & 0.405 & 0.077 \\
& Total (n=92) & $\mathbf{0 . 2 2 7}$ & $\mathbf{0 . 0 4 4 *}$ \\
\hline
\end{tabular}

Pearson parametric correlations ( $R, 2$ tailed) and statistic significance $(p$-value threshold 0.05$)) * p<0.05, * * p<0.01$

(multiparametric) estimates, according to the Rsquared variable, that a variation of $10.3 \%$ of FENO is predicted by a corresponding variation of eosinophils and Ig $\mathrm{E}$ ( $\mathrm{p}=0.031$, Table 3 ). If the age of the patients is taken into account (model 2 in Table 3 ), than a statistically significant prediction of the FENO variation is estimated with $16.5 \%(\mathrm{p}=0.010)$. The last model which includes as predictors a series of secondary parameters (model 3 in Table 3 ) increases the prediction up to $30.4 \%(\mathrm{p}=0.009)$.

The risk for allergic asthma can be statistically estimated with the binary logistic regression analy-
TABLE 3. Multiple linear regression for FENO influenced by the variation of the parameters measured in the subgroups of studied patients

\begin{tabular}{|l|c|c|c|}
\hline $\begin{array}{l}\text { Multiple linear } \\
\text { regression }\end{array}$ & F score & $\begin{array}{c}\text { Adjusted R } \\
\text { squared }\end{array}$ & p-value \\
\hline Model 1 $^{\mathrm{a}}$ & 3.673 & 0.103 & $0.031^{*}$ \\
\hline Model 2 $^{\mathrm{b}}$ & 4.135 & 0.165 & $0.010^{*}$ \\
\hline Model 3 $^{\mathrm{c}}$ & 2.768 & 0.304 & $0.009^{*}$ \\
\hline
\end{tabular}

${ }^{1}$ Dependent variable: FENO (ppb) $(n=92) .{ }^{*} p<0.05,{ }^{*} p<0.01$

andependent variable (predictor): eosinophils (\% num), IgE (IU/ml);

'Independent variable (predictor): eosinophils (\% num), IgE (IU/ml), age;

Independent variable (predictor): eosinophils (\% num), IgE (IU/ml), age, MEF25, FEV1, FVC, MEF75, PEF, MEF50.

sis which reveals that FENO is not a significant biomarker $(p=0.100$, NS) for the risk of allergic asthma, even though its variation can correctly predict almost $76 \%$ of cases, a good, but not strong score (Table 4). Nevertheless, FENO can be successfully used as a predictor for the risk of allergic asthma when combined with eosinophils and IgE in $85 \%$ of the cases ( $<<0.001$, model 2 in Table 4$)$. Taking into account other parameters like age, sex, atopy, rhinitis, positive family history for atopy improves the prediction up to more than $92 \%$. Among these covariables, rhinitis is the only one which is a significant independent predictor $(p=0.001)$, the other parameters not having a significant contribution to the estimation of the risk for allergic asthma (Table 4).

\section{DISCUSSIONS}

The relevance of this research is enhanced by the few similar studies performed so far on the pediatric population (6-13). Children with allergic

TABLE 4. Binary logistic regression for the diagnosis of allergic asthma taking into consideration the variation of the parameters measured for the studied patients

\begin{tabular}{|l|c|c|c|c|c|}
\hline $\begin{array}{l}\text { Binary logistic } \\
\text { regression }\end{array}$ & $\begin{array}{c}\text { Prediction for } \\
\text { allergic asthma (\%) }\end{array}$ & $\begin{array}{c}\text { Chi-square } \\
\text { step }\end{array}$ & $\begin{array}{c}\text { p-value } \\
\text { step }\end{array}$ & $\begin{array}{c}\text { Chi-square } \\
\text { model }\end{array}$ & $\begin{array}{c}\text { p-value } \\
\text { model }\end{array}$ \\
\hline Model 1 $^{\text {a }}$ & 75.9 & - & - & 2.712 & 0.100 \\
\hline Model 2 $^{\mathbf{b}}$ & 84.8 & 36.398 & $<0.001^{* * *}$ & 39.111 & $<0.001^{* * *}$ \\
\hline Model 3 $^{\mathbf{c}}$ & 86.1 & 1.834 & 0.400 & 40.945 & $<0.001^{* * *}$ \\
\hline Model 4 $^{\mathbf{d}}$ & 87.3 & 0.281 & 0.596 & 41.226 & $<0.001^{* * *}$ \\
\hline Model 5 $^{\mathbf{e}}$ & 92.4 & 11.268 & $0.001^{* * *}$ & 52.494 & $<0.001^{* * *}$ \\
\hline Model 6 $^{\mathbf{f}}$ & 91.1 & 1.872 & 0.171 & 54.366 & $<0.001^{* * *}$ \\
\hline
\end{tabular}

${ }^{1}$ Dependent variable: allergic asthma. Chi-square test for the coefficient of parameters (covariates) in model (B)

$* \mathrm{p}<0.05, * * \mathrm{p}<0.01, * * * \mathrm{p}<0.001$.

${ }^{\mathrm{a}}$ Covariate (predictor): FENO (ppb);

${ }^{b}$ Covariate (predictor): FENO (ppb), eosinophils (\% num), IgE (IU/ml);

${ }^{c}$ Covariate (predictor): FENO (ppb), eosinophils (\% num), IgE (IU/ml), age, sex;

${ }^{\mathrm{d} C}$ Covariate (predictor): FENO (ppb), eosinophils (\% num), IgE (IU/ml), age, sex, atopy;

${ }^{e}$ Covariate (predictor): FENO (ppb), eosinophils (\% num), IgE (IU/ml), age, sex, atopy, rhinitis;

${ }^{f}$ Covariate (predictor): FENO (ppb), eosinophils (\% num), IgE (IU/ml), age, sex, atopy, rinhitis, family

history for atopy. 
asthma had significantly higher levels of FENO, eosinophils and total immunoglobulin E.

In our study FENO was statistically correlated with the blood levels of eosinophils and IgE, outlining the correlation between FENO and allergic phenotype. Yao et al. (13) reported the use of FENO for the discrimination of allergic sensitization on a group of children of the same age as ours (5-18 yr). Jackson et al. (9) reported that FENO was significantly associated with atopic status, higher levels being identified especially in children with asthma and atopic dermatitis.

The correlation between FENO and atopic status was also reported by Banovcin et al. (14) who reported higher FENO, total immunoglobulin E, and blood eosinophils in atopic asthmatics in comparison with non-atopic and healthy asthmatic and control children. Welsh et al. (15) performed a multivariate analysis which revealed that asthma along with hay fever and atopic dermatitis influenced FENO levels in pediatric patients. Therefore, atopic asthma is associated with an increase of the FENO levels in comparison with children suffering from non-allergic asthma (14).

Our findings are consistent with Romero et al. (10) who concluded that FENO did not exhibit an accurate ability to identify atopy or asthma alone. We found that FENO becomes a significant predictor only when other parameters like eosinophils, Ig E, age, sex, atopy, rhinitis, positive family history for atopy are taken into account. Therefore, FENO can be regarded as a reliable contributor to the definition of allergic phenotype.

\section{CONCLUSIONS}

The measurement of FENO is a simple investigation, easy to perform, but which requires patients' collaboration in order to obtain valid results.

The interpretation of the FENO values does not correlate with age, nor with the past personal atopic history.

In allergic asthma, FENO value increases when is correlated with serum eosinophils and total immunoglobulin E.

FENO can contribute to the diagnosis of asthma along with respiratory function tests and to the definition of allergic phenotype together with serum eosinophils and total Ig $\mathrm{E}(\mathrm{p}<0,001)$.

\section{REFERENCES}

1. Krantz C., Janson C., Borres M.P., Nordvall L., Alving K., Malinovschi A. Nasal nitric oxide is associated with exhaled NO, bronchial responsiveness and poor asthma control $J$ Breath Res. 2014 Jun; 8(2):026002

2. Nitesh Gupta, Nitin Goel, Raj Kumar. Correlation of exhaled nitric oxide, nasal nitric oxide and atopic status: A cross-sectional study in bronchial asthma and allergic rhinitis Lung India. 2014 Oct-Dec; 31(4): 342-347.

3. Chibana K., Trudeau J.B., Mustovich A.T., et al. IL-13 induced increases in nitrite levels are primarily driven by increases in inducible nitric oxide synthase as compared with effects on arginases in human primary bronchial epithelial cells. Clin Exp Allergy. 2008; 38(6):936-946

4. Dweik R. Exhaled nitric oxide analysis and applications UpToDate Mar 2014

5. Elmasri M., Romero K.M., Gilman R.H. et al. Longitudinal assessment of high versus low levels of fractional exhaled nitric oxide among children with asthma and atopy, Lung. $2014 \mathrm{Apr}$; 192(2):305-12

6. Petsky H.L., Li A.M., Au C.T., Kynaston J.A., Turner C., Chang A.B. Management based on exhaled nitric oxide levels adjusted for atopy reduces asthma exacerbations in children: A dual centre randomized controlled trial. Pediatr Pulmonol. 2014 Jun 2

7. Sivan Y., Gadish T., Fireman E., Soferman R. The use of exhaled nitric oxide in the diagnosis of asthma in school children. J Pediatr. 2009 Aug; 155(2):211-6
8. Jackson D.J., Virnig C.M., Gangnon R.E. et al. Fractional exhaled nitric oxide measurements are most closely associated with allergic sensitization in school-age children J Allergy Clin Immunol. 2009 Nov; 124(5):949-53

9. Romero K.M., Robinson C.L., Baumann L.M. et al. Role of exhaled nitric oxide as a predictor of atopy. Respir Res. 2013 May 2; 14:48.

10. Peirsman E.J., Carvelli T.J., Hage P.Y. et al. Exhaled nitric oxide in childhood allergic asthma management: a randomised controlled trial. Pediatr Pulmonol. 2014 Jul; 49(7):624-31.

11. Ricciardolo F.L., Sorbello V., Ciprandi G. FeNO as biomarker for asthma phenotyping and management. Allergy Asthma Proc. 2015 Jan; 36(1):1-8

12. Yao T.C., Ou L.S., Lee W.I., Yeh K.W., Chen L.C., Huang J.L. PATCH study group. Exhaled nitric oxide discriminates children with and without allergic sensitization in a population-based study. Clin Exp Allergy. 2011; 41:556-564.

13. Banovcin P., Jesenak M., et al. Factors attributable to the level of exhaled nitric oxide in asthmatic children. Eur J Med Res. 2009 Dec 7; 14 Suppl 4:9-13.

14. Welsh L., Lercher P., Horak E. Exhaled nitric oxide: interactions between asthma, hayfever, and atopic dermatitis. In school children. Pediatr Pulmonol. 2007; 42:693-698.

15. Buzoianu E., Moiceanu M., Plesca D.A. Correlation between FENO value and asthma severity. Revista Romana de Pediatrie 2014 Vol. LXIII Nr. 3:249-253 